\title{
Perinatal Mortality: A Dissection of Social Myths, Socioeconomic Taboos and Psychosocial Stress
}

Aleeza Tariq*

Department of Community Health sciences, Agakhan Hospital, Karachi, Pakistan

\begin{abstract}
Background: Several independent and inter-dependent factors contribute in high rates of perinatal mortality. The Aim of this study was to identify community based myths and obscure beliefs that affect maternal health, and to find socio-economic and psychological co-relates impacting on PNM
\end{abstract}

Methods: This small scale, community based study was carried out in June, 2012 at squatter settlements of Karachi. A pretested structured questionnaire was administered to married women of child bearing age (15-49 years) with history of perinatal mortality.

Results: Out of 55 successfully surveyed women, $63.6 \%$ did not take antenatal care; $40.9 \%$ due to 'infertility' myth; $22.7 \%$ had no access. Generally women were of poor health; $52.7 \%$ weighed $40-50 \mathrm{~kg}, 43.6 \%$ were severely anaemic. The literacy rate among surveyed women was very low; $63.6 \%$ were illiterate. During pregnancy, $34.5 \%$ did household work for 6-8 hours in a typical day; and $38.2 \%$ were pressurized for sons. The rate of betel nut, tobacco and drug addiction was high among them $67.3 \%, 50.9 \%, 25.5 \%$, respectively. The majority (40\%) of husband's worked as fisherman and $76.4 \%$ had their husband's income $<5,000$ per month. $74.5 \%$ lived in joint families. $47.3 \%$ of their babies were of low birth weight $(<2.5 \mathrm{~kg}$ ) and $38.2 \%$ died in first 12 hours; asphyxia caused $30.9 \%$ of these deaths while $29.1 \%$ were due to pre-eclampsia. However, $14.5 \%$ mothers believed it was due to God's will. $54.5 \%$ new-borns were male and $45.5 \%$ female.

Conclusion: In order to reduce perinatal mortality, it's important not only to make antenatal care accessible but also acceptable and available. Due efforts are required in educating women about the health benefits of antenatal care, and increasing women's overall awareness to help them uplift their physical and mental health, and social, and economic wellbeing in community.

Keywords: Perinatal mortality; Social myths; Socioeconomic

\section{Introduction}

Perinatal mortality is a global challenge. However, developing countries have to bear the brunt of it, accounting for $98 \%$ of perinatal deaths [1]. World Health Organization (WHO) defines perinatal mortality as deaths occurring during late pregnancy ( $>22$ weeks of gestation), during birth and within seven days after delivery $[1,2]$. The perinatal period is considered the most critical phase of Life [2-4]. Globally there are about 130 million babies born every year of which 4 million die in the first 4 Weeks and 3.3 million are still births [1,5]. In Pakistan, about 5.3 million births occur yearly out of which 2,70,000 new borns die. This high perinatal mortality is 10 times higher than that in Unites States $[5,6]$.

It would be difficult to achieve The Millennium Development goal of reducing child mortality by two thirds by 2015 without reducing perinatal death [2,7]. The Perinatal mortality rates reported for Pakistan are between 61-81/1,000 [5,8]. A demographic survey in Karachi reported 54/1000 [5,9]. Rural and per urban survey from Lahore reported 67/1000 [5,10].

Surveys previously conducted were largely hospital based focusing on socio-biological determinants. The importance of this research lies in unfolding community practised social myths, socioeconomic and psychosocial stresses contributing in high perinatal mortality.

\section{Objective}

To lay out in open, various community based social myths, socioeconomic and psychosocial taboos causing an increase in PNM.

\section{Methodology}

A small scale, community based, retro-grade, cross sectional survey was conducted by a learning researcher in the month of June, 2012. Study was conducted in an urban squarter, Rehri Goth, a coastal fishing village in Pakistan, located on Arabian Sea coast, comprising of the community of fishermen and laborers [11]. Included in the survey were a total of 55 married women of reproductive age (15-49 years) having a history of perinatal mortality (still births and early neonatal deaths).

They were conveniently surveyed by a structured questionnaire preceded by informed consent, filled by researcher. It inquired about various dimensions affecting PNM.

1) Socioeconomic and Demographic Variables (mother's education, occupation, income, father's occupation and income, age, weight, maternal disease, parity, household information, no. of meals, constituent of meals, water and sanitation conditions, drug, smoking, gutka history).

*Corresponding author: Aleeza Tariq, Department of Community Health sciences, Agakhan Hospital, Karachi, Pakistan, E-mail: arian_outrageous@hotmail.com

Received August 14, 2012; Accepted October 22, 2012; Published October 24, 2012

Citation: Tariq A (2012) Perinatal Mortality: A Dissection of Social Myths, Socioeconomic Taboos and Psychosocial Stress. J Neonatal Biol 1:111. doi:10.4172/2167. 0897.1000111

Copyright: (C) 2012 Tariq A. This is an open-access article distributed under the terms of the Creative Commons Attribution License, which permits unrestricted use, distribution, and reproduction in any medium, provided the original author and source are credited. 
Citation: Tariq A (2012) Perinatal Mortality: A Dissection of Social Myths, Socioeconomic Taboos and Psychosocial Stress. J Neonatal Biol 1:111. doi:10.4172/2167-0897.1000111

2) Biological and Psychological Determinants (no. of pregnancies experienced, hours of work daily during pregnancy, no of full term, premature, still births, neonatal deaths experienced, antenatal care if taken, vaccination history, if pressured for giving birth to sons, antenatal, postnatal complications and psychosocial stress faced in each pregnancy).

3) Details of New Born (sex, congenital anomaly, birth weight if known, history of birth asphyxia, umbilical cord anomaly).

\begin{tabular}{|c|c|c|}
\hline RISK FACTORS & PERCENTAGES & $\begin{array}{c}\text { NUMBERS } \\
\mathrm{N}=55\end{array}$ \\
\hline $\begin{array}{l}\text { Maternal education: } \\
\text { Primary level } \\
\text { Secondary level } \\
\text { Illiterate }\end{array}$ & $\begin{array}{c}30.9 \% \\
5.5 \% \\
63.6 \%\end{array}$ & $\begin{array}{l}17 \\
03 \\
35\end{array}$ \\
\hline $\begin{array}{l}\text { Time elapsed since last delivery: } \\
<1 \text { year } \\
2 \text { year } \\
3 \text { year } \\
4 \text { year } \\
5 \text { year } \\
6 \text { year } \\
7 \text { year }\end{array}$ & $\begin{array}{c}36.4 \% \\
14.4 \% \\
1.8 \% \\
5.5 \% \\
5.5 \% \\
5.5 \% \\
9.1 \%\end{array}$ & $\begin{array}{c}20 \\
9 \\
1 \\
3 \\
3 \\
3 \\
5\end{array}$ \\
\hline $\begin{array}{l}\text { Marriage: } \\
\text { Inside family } \\
\text {-first cousin } \\
\text {-second cousin } \\
\text { Outside }\end{array}$ & $\begin{array}{c}74 . .5 \% \\
73.17 \% \\
26.83 \% \\
23.6 \%\end{array}$ & $\begin{array}{l}41 \\
30 \\
11 \\
13\end{array}$ \\
\hline $\begin{array}{l}\text { Husband's income: } \\
<5,000 \\
5-10,000 \\
10,001-15,000 \\
15,001-20,000\end{array}$ & $\begin{array}{c}76.4 \% \\
20 \% \\
1.8 \% \\
1.8 \%\end{array}$ & $\begin{array}{c}42 \\
11 \\
1 \\
1\end{array}$ \\
\hline $\begin{array}{l}\text { Own income } \\
<5,000 \\
5-10,000\end{array}$ & $\begin{array}{c}30.9 \% \\
5.5 \%\end{array}$ & $\begin{array}{c}17 \\
3\end{array}$ \\
\hline $\begin{array}{l}\text { Diet: } \\
\text { Balanced: } \\
\text { Un-balanced: }\end{array}$ & $\begin{array}{l}49.1 \% \\
50.9 \%\end{array}$ & $\begin{array}{l}27 \\
28\end{array}$ \\
\hline $\begin{array}{l}\text { Living conditions: } \\
\text { Poor } \\
\text { Satisfactory } \\
\text { Good }\end{array}$ & $\begin{array}{l}65.5 \% \\
23.6 \% \\
10.9 \%\end{array}$ & $\begin{array}{c}36 \\
13 \\
6\end{array}$ \\
\hline $\begin{array}{l}\text { Family status: } \\
\text { Joint family } \\
\text { Nuclear family }\end{array}$ & $\begin{array}{l}74.5 \% \\
25.5 \%\end{array}$ & $\begin{array}{l}41 \\
14\end{array}$ \\
\hline $\begin{array}{l}\text { Water and sanitation: } \\
\text { Poor } \\
\text { Satisfactory } \\
\text { Good }\end{array}$ & $\begin{array}{l}65.5 \% \\
21.8 \% \\
12.7 \%\end{array}$ & $\begin{array}{c}36 \\
12 \\
7\end{array}$ \\
\hline $\begin{array}{l}\text { No. of hours of work during } \\
\text { pregnancy: } \\
2-4 \text { hrs. } \\
4-6 \text { hrs. } \\
6-8 \text { hrs. } \\
8-10 \text { hrs. }\end{array}$ & $\begin{array}{l}18.2 \% \\
34.5 \% \\
34.5 \% \\
12.7 \%\end{array}$ & $\begin{array}{c}10 \\
19 \\
19 \\
7\end{array}$ \\
\hline $\begin{array}{l}\text { Iron and folic acid intake during } \\
\text { pregnancy: } \\
\text { Taken } \\
\text { Not taken }\end{array}$ & $\begin{array}{l}43.6 \% \\
56.4 \%\end{array}$ & $\begin{array}{l}24 \\
31\end{array}$ \\
\hline $\begin{array}{l}\text { Maternal disease: } \\
\text { Signs of anemia } \\
\text { Eclampsia } \\
\text { Pre-eclampsia } \\
\text { Gestational diabetes } \\
\text { Asthma } \\
\text { APH } \\
\text { PPH } \\
\text { Obstructed labor } \\
\text { Puerperal sepsis }\end{array}$ & $\begin{array}{c}5.5 \% \\
23.6 \% \\
3.6 \% \\
7.3 \% \\
23.6 \% \\
16.4 \% \\
6.4 \% \\
3.6 \%\end{array}$ & $\begin{array}{c}3 \\
13 \\
2 \\
4 \\
13 \\
9 \\
9 \\
2\end{array}$ \\
\hline
\end{tabular}

Table 1: Socioeconomic and Demographic Factors Related To Pnm.

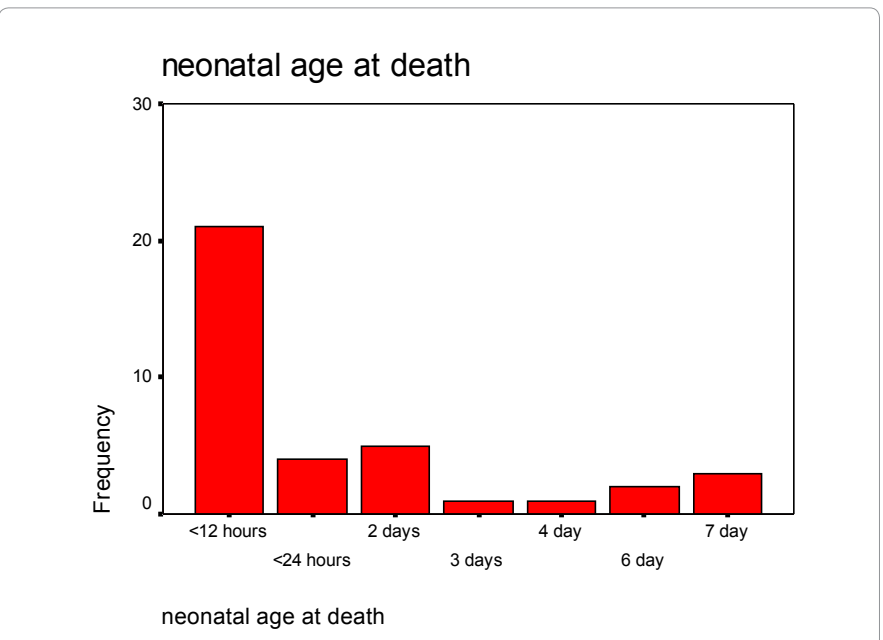

Figure 1: $38.2 \%(n=21)$ neonatal deaths occurred in less than 12 hours after birth, $7.3 \%(n=4)$ in less within 24 hours.

\section{Birth-weight of newborn $(n=55)$}

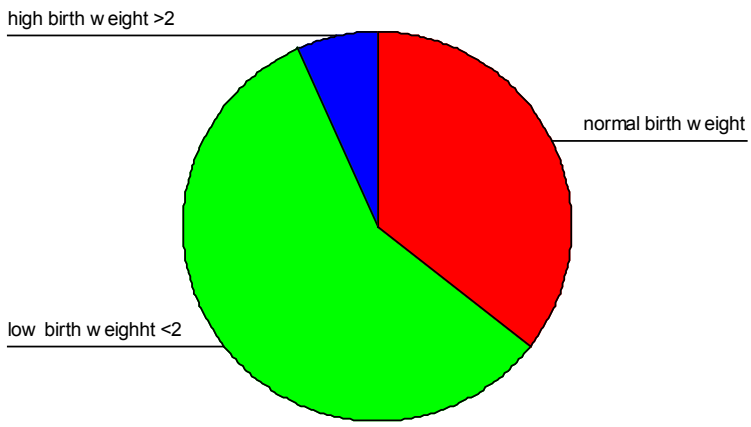

Birth w eight in KGS (no.of cases)

Figure 2: Majority of newborns, $47.3 \%(n=26)$ were low birth weight $<2.5 \mathrm{Kg}$ Normal birth weight of $2.5 \mathrm{Kgs}$ were $29.1 \%(n=16)$ and those with birth weigh $>2.5 \mathrm{Kgs}$ were $5.5 \%(\mathrm{n}=3)$. Since, it was retrospective survey exact weight of the neonate was not determined, had to rely over hospital records and mother's memory.

\section{Results}

Outcome of the study showed that out of 55 surveyed women with a history of perinatal mortality, $38.2 \%$ were pressurized for sons; rate of drug and tobacco addiction was high amongst them. Generally, $67.3 \%$ were addicted to betel nuts and gutka, 50.9\% to tobacco and $25.5 \%$ to drug intake. Psychological stress was faced by $40 \%$ (confirmed through emotional and behavioral symptoms) during pregnancy. Majority of surveyed females $63.6 \%$ did not take antenatal care, $40.9 \%$ of them due to some myth while $22.7 \%$ had no access to antenatal care (Table 1).

\section{Psychosocial Factors}

During our survey, $38.2 \%$ females reported that they were pressurized for giving birth to sons while $61.8 \%$ were not. Addiction to betel nuts and gutka, tobacco and drug intake were $67.3 \%, 50.9 \%$, $25.5 \%$, respectively. Psychological stress was experienced by $40 \%$ 
cause of neonatal deaths

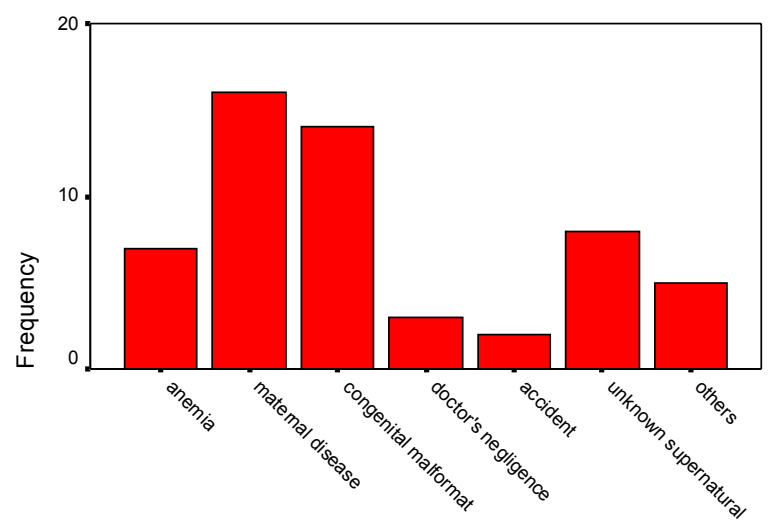

what caused neonatal death according to you

Figure 3: According to mothers, $29.1 \%(n=16)$ deaths were due to her own disease out of which vast majority were due to Pre-eclampsia. Of significance here was $14.5 \%(n=8)$ reported that neonatal death was either due to God's will or supernatural powers. A study has reported 64/1000 PNDs due to eclampsia and $56 \%$ of severe perinatal complications $[5,11]$.

(confirmed through emotional and behavioral symptoms) during pregnancy. Majority of females (63.6\%) did not take antenatal care, $40.9 \%$ of them due to some myth while $22.7 \%$ had no access to antenatal care.

\section{Antenatal and Post Natal Factors}

TTV vaccinations were not taken by $63.5 \%$. Deliveries took place $65.5 \%$ at home, $34.5 \%$ hospital. Method of delivery $89.1 \%$ NVD, $4.2 \%$ CS. Deliveries was conducted by mother-in-law $41.8 \%$, LD $36.4 \%$, TBA $20 \%$, and LHV $1.8 \%, 1.8 \%$ forceps. $54.5 \%$ newborns were male and $45.5 \%$ females. Majority of neonatal deaths were due to birth asphyxia 30.9\% (Figures 1-3).

\section{Discussion}

Pakistan has rich heritage of social myths, spanning several decades, diffusing through linguistic, racial, geographical and socioeconomic barriers. However, with better conditioning of mind through education many of these detrimental myths have washed away in upper and middle socioeconomic setups. Unfortunately, in orphanage areas like rural and outskirts of urban it still persists as a plague. Underlying rationale behind endemicity of social myths is being deserted from basic education. More than $60 \%$ of men and $90 \%$ of women have received no formal schooling or education (IUCN, 2003).

Among many myths, stories, or old wives' tales, is the belief that is passed arduously in Rehri Goth and directly implicated in perinatal mortality was the probability of acquiring 'infertility' with antenatal care taken. The majority of surveyed females (63.6\%) did not take antenatal care during their pregnancy, $40.9 \%$ of them due to 'infertility' myth while $22.7 \%$ had no access to antenatal care.

Another myth that was found among Rehri Goth women was that by eating less the child will be born easier through the normal vaginal delivery. The consequence of this myth often leads to malnourishment and low birth weight for the child sometimes resulting in death. There is also a belief that home delivery is a better option than that of a hospital. These decisions create barriers to the delivery of a healthy child.
Perinatal mortality itself is governed by many factors including the 'myth' factor which is largely over-looked and yet is a significant contributor in many developing nations. Any stigma to form and prosper requires several culture influenced factors. To overcome them requires multi-dimensional prolong efforts in various sectors. Perinatal mortality jeopardizes maternal health and life accounting for high maternal morbidity and mortality in Pakistan. It is important not only to make ante-natal care accessible but also to make it acceptable and available. Proper education regarding benefits of antenatal care and surveillance programs can help in reducing PNM.

Another significant culprit present in Rehri Goth particularly and largely in developing nations like Pakistan is the pressure inflicted on pregnant females for bearing sons. Survey results showed (38.2\%) females were pressurized for sons. Higher rate of drug usage, tobacco in the form of shisha and gutka, betel nuts were seen among these pressurized females. Study has shown that perinatal mortality increases directly with the level of maternal smoking during pregnancy. Increases in smoking level are associated with increases in the frequency of early fetal deaths and of neonatal deaths [12].

Psychological stress was reported by $40 \%$ during their pregnancy. Factors causing such stress were intense house hold work for 6-8 (34.5\%) hours per day, economic instability (76.4\% men had temporary earning of less than 5,000/month $<52.97 \mathrm{USD} /$ month), poverty, pressure for sons, and unbalanced diet (50.9\%). Along with malnutrition, maternal health is affected by manual labor (getting water and fuel for their households). Moreover, the fertility rates among such women are high. The high energy demands on poor women from their combined productive and reproductive roles together with malnutrition thus have a substantial impact on their health. This is further compounded by poor health care. Children born to underweight and stunted women are also likely to be underweight and stunted which affect their future potential at the individual and community level [13].

Illiteracy, unskilled labor, poor living conditions, disparity among kids, preference for male child results as malnutrition, poor maternal health, antenatal and postnatal complications and eventually an increase in perinatal mortality.

\section{References}

1. Zupan J, Aahman E (2005) Perinatal mortality for the year 2000: estimates developed by WHO. Geneva: World Health Organization 2005.

2. Emmanuel T, Notion G, Gerald S, Addmore C, Mufuta T, et al. (2011) Determinants of perinatal mortality in Marondera district, Mashonaland East Province of Zimbabwe, 2009: a case control study. Pan African Medical Journal 8: 7.

3. Bhardwaj N, Hasan SB, Zaheer M (1995) Maternal care receptivity and its relation to perinatal and neonatal mortality. a rural Study. Indian Pediatr 32: 416-423.

4. Behl L, Grover N, Kaushik SL (1998) Perinatal and Neonatal mortality--A Hospital Based Study. Indian Pediatr 35: 683-684.

5. Shamshad (2010) Perinatal Mortality: An Outcome of Quality of Perinatal Care. Gomal Journal of Medical Sciences 8.

6. Ali N (2010) State of the worlds new born. Save the Children-Pakistan.

7. Haines A, Cassels A (2004) Can the millennium development goals be attained? BMJ 329: 394-397.

8. Unicef Basic Indicators. Pakistan Statistics. 
Citation: Tariq A (2012) Perinatal Mortality: A Dissection of Social Myths, Socioeconomic Taboos and Psychosocial Stress. J Neonatal Biol 1:111. doi:10.4172/2167-0897.1000111

Page 4 of 4

9. Fikree FF, Gray RH (1996) Demographic survey of the level and determinants of perinatal mortality in Karachi, Pakistan. Paediatr Perinatal Epidemol 10 86-96

10. Jalil F, Lindblad BS, Hanson LA, Khan SR, Yaqoob M, et al. (1993) Early child health in Lahore, Pakistan: IX. Perinatal events. Acta Paediatr suppl 82: 95-107.
11. Bhaktiar UJ, Khan Y, Nasar R (2007) Relationship between maternal hemoglobin and perinatal outcome. RMJ 32: 102-104.

12. Meyer MB, Tonascia JA (1977) Maternal smoking, pregnancy complications, and perinatal mortality. Am J Obstet Gynecol 128: 494-502.

13. A visit to rehrigoth, a study team from HOPE (Health Oriented Preventive Education) carried out survey. 